\title{
Review Paper: Global Prevalence of Workplace Violence Against Paramedics: ASystematic Review and Meta-analysis
}

\author{
Hamidreza Shabanikiya $^{1}$ (D, Fatemeh Kokabisaghi ${ }^{1}$, Morteza Mojtabaeian², Tara Sahebi ${ }^{2}$, Mehdi Varmaghani ${ }^{\text {* }}$ (D) \\ 1. Department of Management Sciences and Health Economics, School of Health, Mashhad University of Medical Sciences, Mashhad, Iran \\ 2. Student Research Committee, School of Health, Mashhad University of Medical Sciences, Mashhad, Iran.
}

\begin{tabular}{|l|l|}
\hline $\begin{array}{c}\text { Use your device to scan } \\
\text { and read the article online }\end{array}$ & $\begin{array}{l}\text { Citation Shabanikiya M, Kokabisaghi F, Mojtabaeian M, Sahebi T, Varmaghani M. Global Prevalence of Workplace Violence } \\
\text { Against Paramedics: A Systematic Review and Meta-Analysis. Health in Emergencies and Disasters Quarterly. 2021; 6(4):205-216. } \\
\text { http://dx.doi.org/10.32598/hdq.6.4.259.3 }\end{array}$ \\
dol'http://dx.doi.org/10.32598/hdq.6.4.259.3
\end{tabular}

\section{(i) (5)}

Article info:

Received: 18 Dec 2020

Accepted: 15 May 2021

Available Online: 01 Jul 2021

\section{Keywords:}

Paramedics, Workplace violence, Meta-analysis, Assaultive Behavior

\section{ABSTRACT}

Background: Violence is increasing in societies and workplaces around the world. This study aimed to review the literature on violence against paramedics in the prehospital setting and estimate the related exposure rates and types.

Materials and Methods: The study was conducted based on the guidelines of systematic reviews and meta-analyses. The literature on the prevalence of workplace violence against paramedics published from January 1990 to September 2019 was searched in PubMed, Web of Science, Scopus, ProQuest, and Embase databases. The prevalence of violence was measured by using the random-effects model in Stata software. Sub-group analysis and meta-regression models were applied to explain the sources of heterogeneities.

Results: The prevalence of overall violence, physical violence, verbal violence, and sexual harassment among study subjects were calculated to be 0.66 (95\% CI CI: $0.20-1.11), 0.25$ (CI: 0.16- 0.34), 0.58 (CI: 0.29-0.86) and 0.16 (CI: 0.09-0.22), respectively. There was no significant difference between male and female paramedics in terms of violence types. However, the prevalence of sexual harassment among women was higher than men $(24 \%$ vs. $6 \%$ ). The highest rate of physical violence and sexual harassment belonged to Europe and North America, while they had the lowest verbal violence. Asia and Australia had the lowest rate of physical violence and sexual harassment.

Conclusion: Prehospital emergency service providers face a higher risk of potential exposure to violence in health care settings. This issue necessitates the special attention of prehospital care administrators to reduce the risk and related consequences of workplace violence by taking effective measures.

\footnotetext{
* Corresponding Author:

Mehdi Varmaghani, $P h D$.

Address: Department of Management Sciences and Health Economics, School of Health, Mashhad University of Medical Sciences, Mashhad, Iran.

E-mail:varmaghanim@mums.ac.ir
} 


\section{Introduction}

iolence is increasing in societies and V workplaces around the world [1]. Workplace Violence (WPV) occurs everywhere, but it is significantly higher in health care organizations [2-4]. International Council of Nurses reported that healthcare workers are more likely to be attacked at the workplace than police officers and prison guards [5]. Although there are broad categories of occupational violence, it can be divided into three types: verbal, physical, and sexual (sexual harassment \& assault) [6-8].

The study findings in the United States showed that the rate of violence in all professions is 12 per 1000 persons, while in occupations related to health services, it is approximately 22 per 1000 [9]. Although most studies focused on nurses, WPV in the health care domain is not limited to this group and includes other clinical staff, including physicians and emergency medical staff [10-12]. Emergency medical staff are more likely to be exposed to violence based on the nature of their jobs that requires providing services at patients' houses or workplaces and generally outside the hospital [7, 13, 14]. Furthermore, close interaction with patients and their companions and bystanders in stressful conditions increases the risk of violence [15].

Violence in the workplace has both personal and organizational consequences [16]. At the individual level, acts of violence adversely affect the physical and mental health of employees. Reports indicate that the rate of occupational injuries among paramedics is five times more than the average rate of all occupations; most of it is due to the act of violence [17]. Moreover, the occupational mortality rate is high among paramedics, equivalent to police officers and firefighters. The third leading cause of occupational mortality is the act of violence [18]. Burnout, stress, and anxiety are some of the psychological effects of violence against paramedics [19]. The prevalence of posttraumatic stress disorder, as one of the most well-known and common complications after incidents (such as acts of violence), is $20 \%$, which is higher than the average for all other occupations [20]. The statistics might be higher due to the deficiency of rules, policies, and mechanisms to compel and support reporting violence against paramedics, similar to other professions such as police officers and firefighters [21].

It has been proven that violence against paramedics adversely affects their performance, leading to a decline in the quality of services provided to patients $[19,22$, 23]. WPV against paramedics, compared to other health- care professionals such as nurses, is of great importance, while it has been inadequately studied $[13,24]$. Also, in the studies, the reported prevalence rates are scattered. So it is challenging to determine each type of violence among prehospital emergency medical staff.

Although some systematic reviews have been conducted about WPV, they only integrated the findings of other studies, and a standard meta-analysis was not performed on quantitative results. One of these studies was the study of Maguire et al. [12], in which the findings of studies on violence against prehospital emergency staff published from 2000 to 2016 were synthesized. In another study, Pourshaikhian et al. [24] systematically reviewed the literature on violence against the staff of Emergency Medical Services (EMS) over 25 years (1990-2014) and presented their results narratively. In the only systematic review and meta-analysis found in this field, Sahebi et al. [25] used meta-analysis to determine the prevalence of violence among Iranian EMS staff. Clearly, this review did not encompass international EMS personnel. Considering the gap of knowledge in this field and the importance of occupational violence among EMS employees, we aimed to review the literature on the violence against paramedics in the prehospital setting and estimate exposure rates by the types of violence. These estimates show the extent and severity of the problem, which is the starting point for designing and implementing any policy or intervention to reduce the violence against paramedics. Moreover, we specified the findings on violence exposure by gender and world regions.

\section{Materials and Methods}

\section{Search strategy}

This systematic review and meta-analysis was conducted based on Preferred Reporting Items for Systematic Reviews and Meta-Analyses (PRISMA) [26]. All articles that reported the prevalence of WPV against paramedics were searched in PubMed (including MeSH and Entrée terms), Web of Science (ISI), Scopus, ProQuest, and Embase databases by the following search terms: "paramedic", "violence", "emergency medical technicians", "prehospital”, “ WPV”, “ Sexual Harassment”, and "Sex Offenses". Key operators such as "AND" and "OR" were used to incorporate search terms. EndNote software (version X7) was used for searching, downloading, and managing relevant articles. For analyzing the extracted results of eligible studies, Stata version 12 was used. In addition, we searched all the reference lists of selected papers to avoid missing any relevant articles. 


\section{Inclusion and exclusion criteria}

All published studies on prehospital emergency staff were included. The studies that included other staff, such as police officers and firefighters, were excluded because the findings related to prehospital emergency staff cannot be separated from other employees. The period of the search was from January 1990 to September 2019. Furthermore, we excluded all studies that were published in languages other than English and duplicated studies. To conduct the meta-analysis, eligible studies were screened in three phases. First, the titles and abstracts of all papers were evaluated by two independent reviewers. Then, the full texts of selected studies were reviewed, and the probable disagreements between two assessors were resolved by the principal investigator, who made decisions on controversial articles. Finally, the data were extracted by two independent reviewers for carrying out a meta-analysis.

\section{Data extraction}

The data extracted from eligible studies were entered into a template prepared in a Microsoft Excel spreadsheet. The variables included the name of the first author, publication year, study area, study design, sample size, age-groups and the gender of participants, response rate, and the number of participants exposed to violence. The primary data were extracted by two reviewers and a third investigator who controlled the process. The characteristics of the studies are shown in Table 1.

\section{Quality assessment}

The quality of each relevant article was assessed using the global burden of disease quality assessment checklist [36]. This checklist has been used in similar studies [37-40]. The range of total quality score was within $0-13$. Key criteria for assessing the quality of included studies were the sample size (0-3 score), the response rate (0-6 score), and the sampling method (1-4 score).

\section{Statistical analysis}

The prevalence of violence was measured using a random-effects model through metaprop in Stata statistical software v. 12). A Forest plot was used for presenting the results of the study. Heterogeneity between the included studies was evaluated by I2 statistic and Cochran's $\mathrm{Q}$ test. Sub-group analysis and meta-regression models were conducted to demonstrate the sources of heterogeneities. In the meta-regression model, we applied several variables, including sampling method, publication year, level of study, and quality score in univariate levels. Furthermore, a funnel plot was used for evaluating the publication bias. Egger's test was applied to determine the significance of publication bias (significant level: 0.05).

\section{Results}

In the first searching phase, 20809 papers were found, including 20473 in PubMed, 151 in Web of Science, 142 in Scopus, 35 in ProQuest, and 8 in Embase. In the next phase, 580 papers were removed by taking the duplicates out. Then, 20229 records were selected for screening based on the titles and abstracts and then full texts. Eventually, a total of 11 papers with 8694 participates were chosen to be included in the meta-analysis (Figure 1).

\section{The estimated prevalence of violence}

We used metaprop comment to calculate physical, verbal, sexual harassment, and total violence in Stata software (version 12). Using the random model, the prevalence of overall violence among study subjects was 0.66 (CI: 0.20-1.11) (Figure 2).

The prevalence of physical violence was 0.25 (CI: 0.16- 0.34) (Figure 3). In addition, the prevalence of verbal violence and sexual harassment among subjects were 0.58 (CI: 0.29-0.86) and 0.16 (CI: 0.09-0.22), respectively. Among different types of violence, verbal violence was the most risk, and sexual harassment had the least risk for paramedics. The prevalence of different types of violence by gender is shown in Table 2 and by continents and areas of the world in Table 3.

\section{Quality of studies}

In our results, most publications had a cross-sectional design (10 studies). Their sample sizes were significantly different (with a mean of almost 1421 participants). The sampling methods varied substantially, including census, random stratified sampling, and simple random sampling. The level of included studies was national and subnational. Moreover, the diversity of response rate was considerable $(10 \%$ to $89 \%)$.

\section{Meta-regression and publication bias}

Univariate meta-regression analysis was applied to identify the sources of heterogeneity (Table 4). We considered 0.1 as the significance level of analysis in the univariate model because of the limited extent of literature. Among all variables used for analyzing the univariate model, only the publication year could justify the $30 \%$ of 
Table 1. Characteristics of the included studies
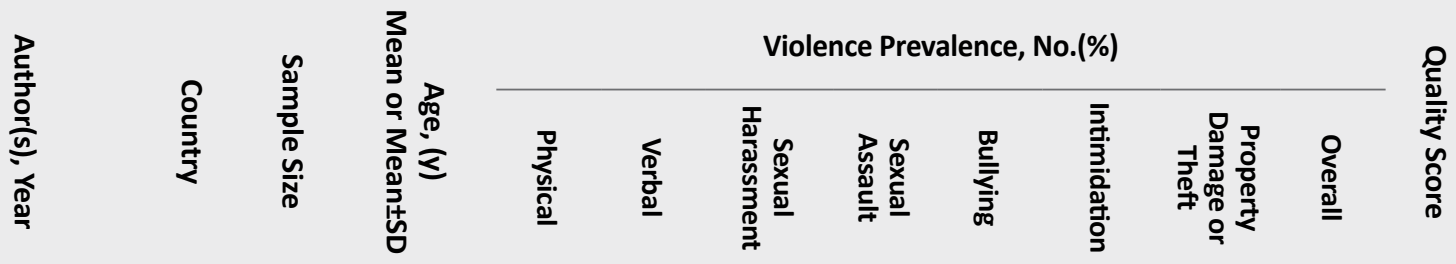

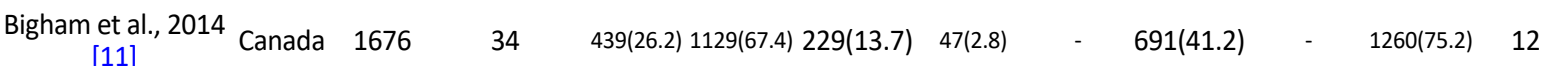

Boyle et al., 2007 [27]

Australia 255

41

$96(37.6) \quad 210(82.4) \quad 42(16.5) \quad 11(4.3)$

$\begin{array}{llll}139(54.5) & 38(14.9) & 223(87.5) \quad 6\end{array}$

Boyle \& McKenna 2017 [28]

$24.1 \quad 1(0.08) 28(21.2) \quad 1(0.08) \quad 0(0)$

13(9.9)

5

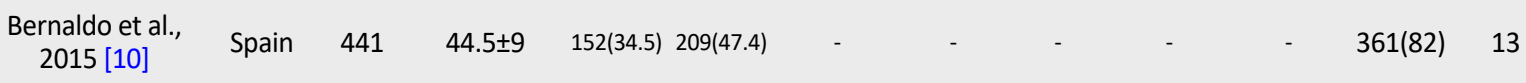

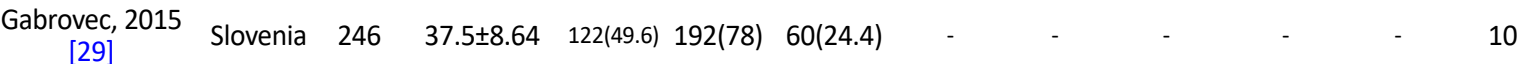

Grang et al., 2002

[30]

USA 4102

$38(0.92) 90(2.19)$

$184(4.5) \quad 12$

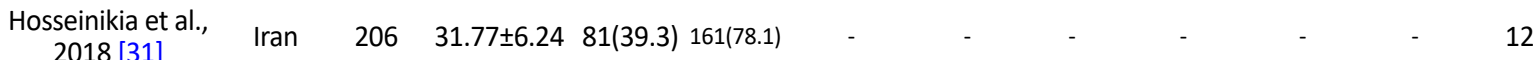

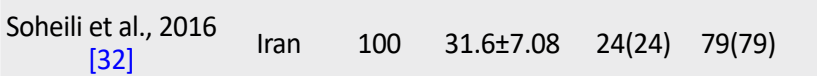

Wongtongkam, Australia $48 \quad 39.19 \pm 10.19 \quad 16(33.33) 34(70.8)$

Yılmaz et al., 2015

[34]

$\begin{array}{lllll}\text { Turkey } & 141 & 30.3 \pm 9.2 & 12(8.5) & 73(51.77)\end{array}$

9

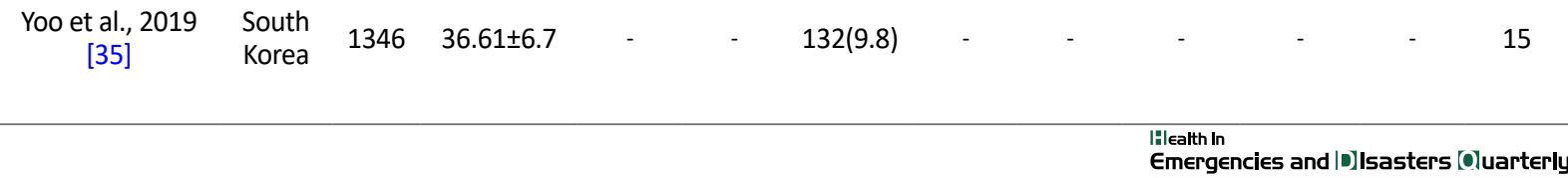




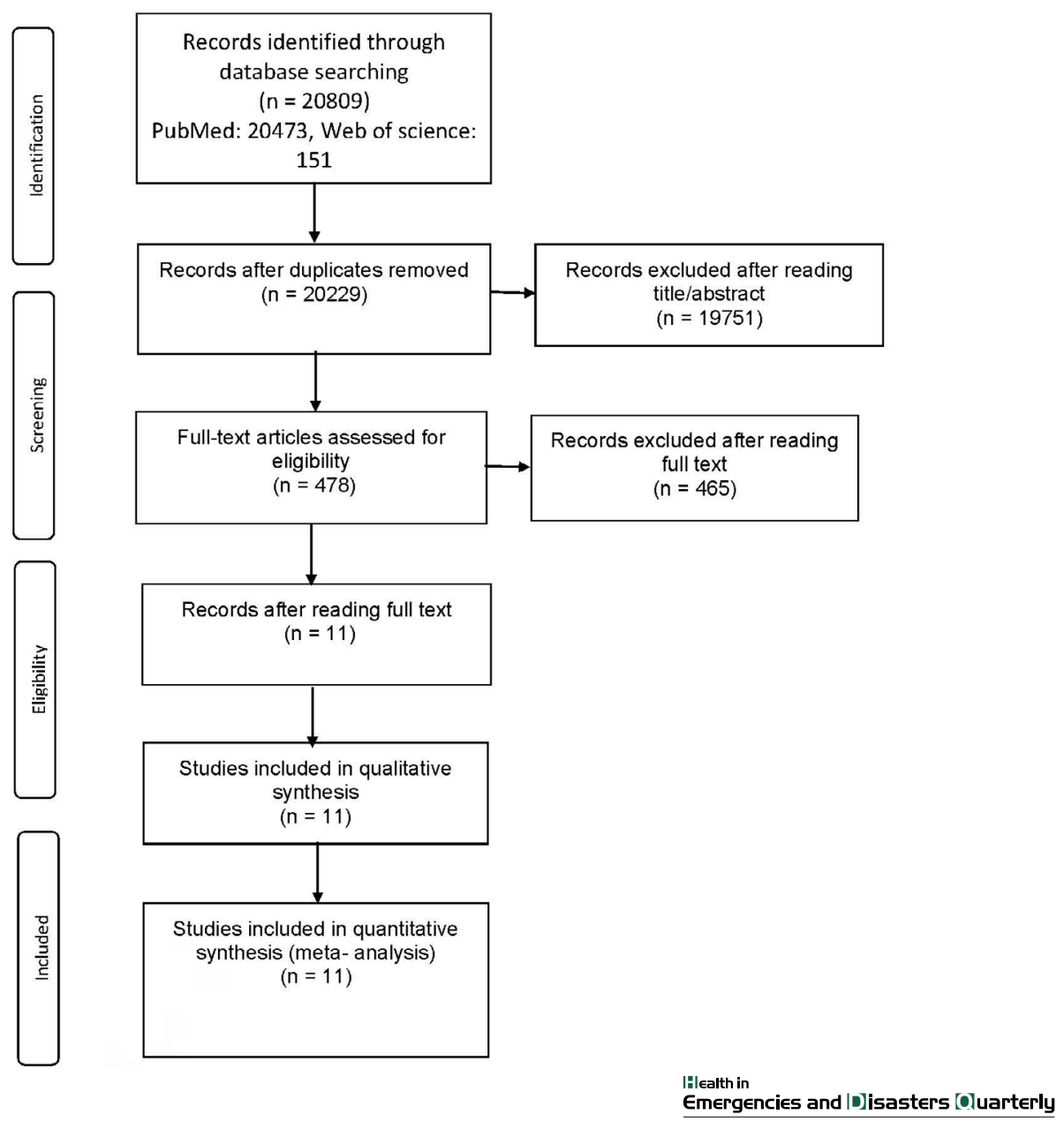

Figure 1. The process of search and selection of studies on workplace violence against paramedics (JPG format)

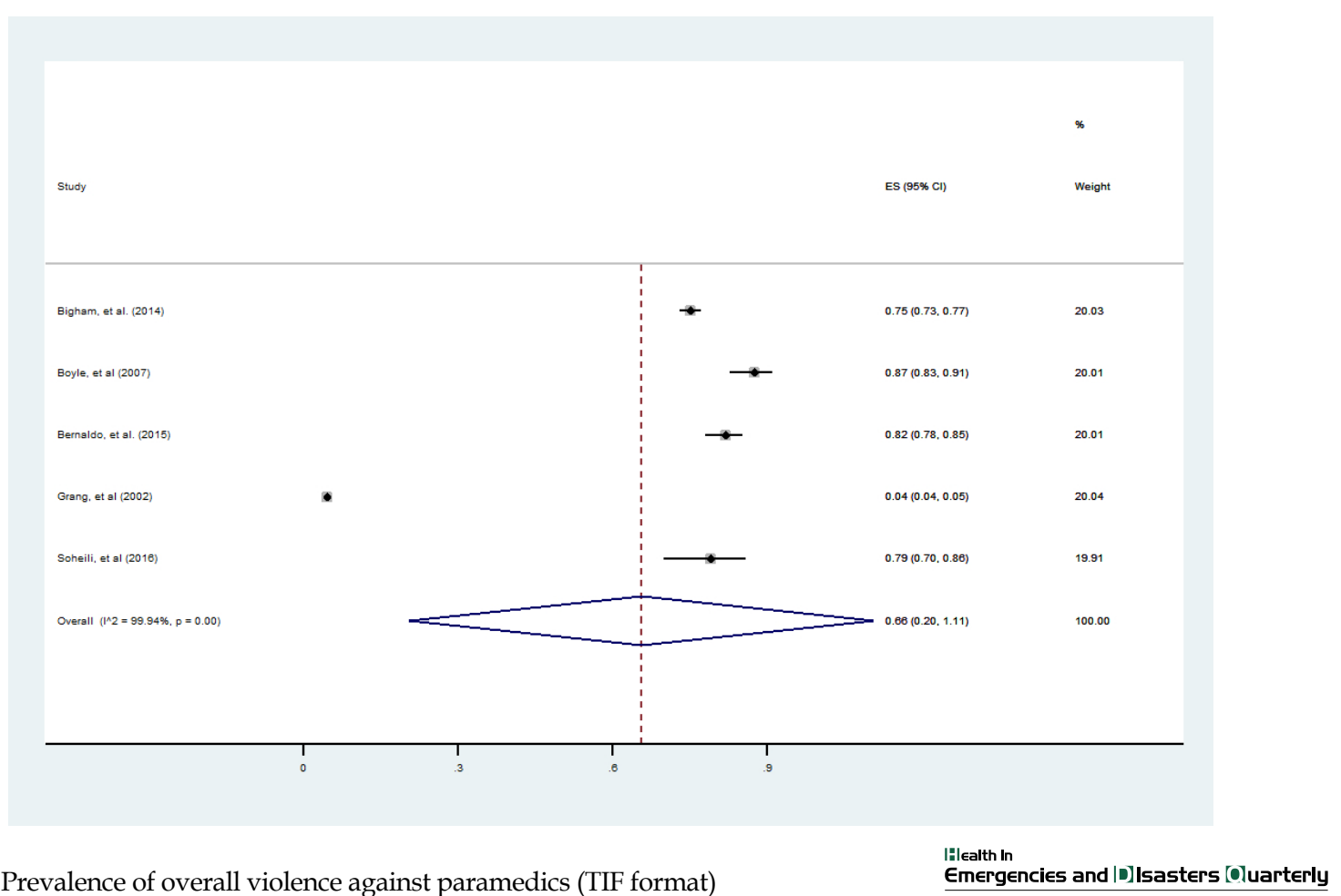

Figure 2. Prevalence of overall violence against paramedics (TIF format) 


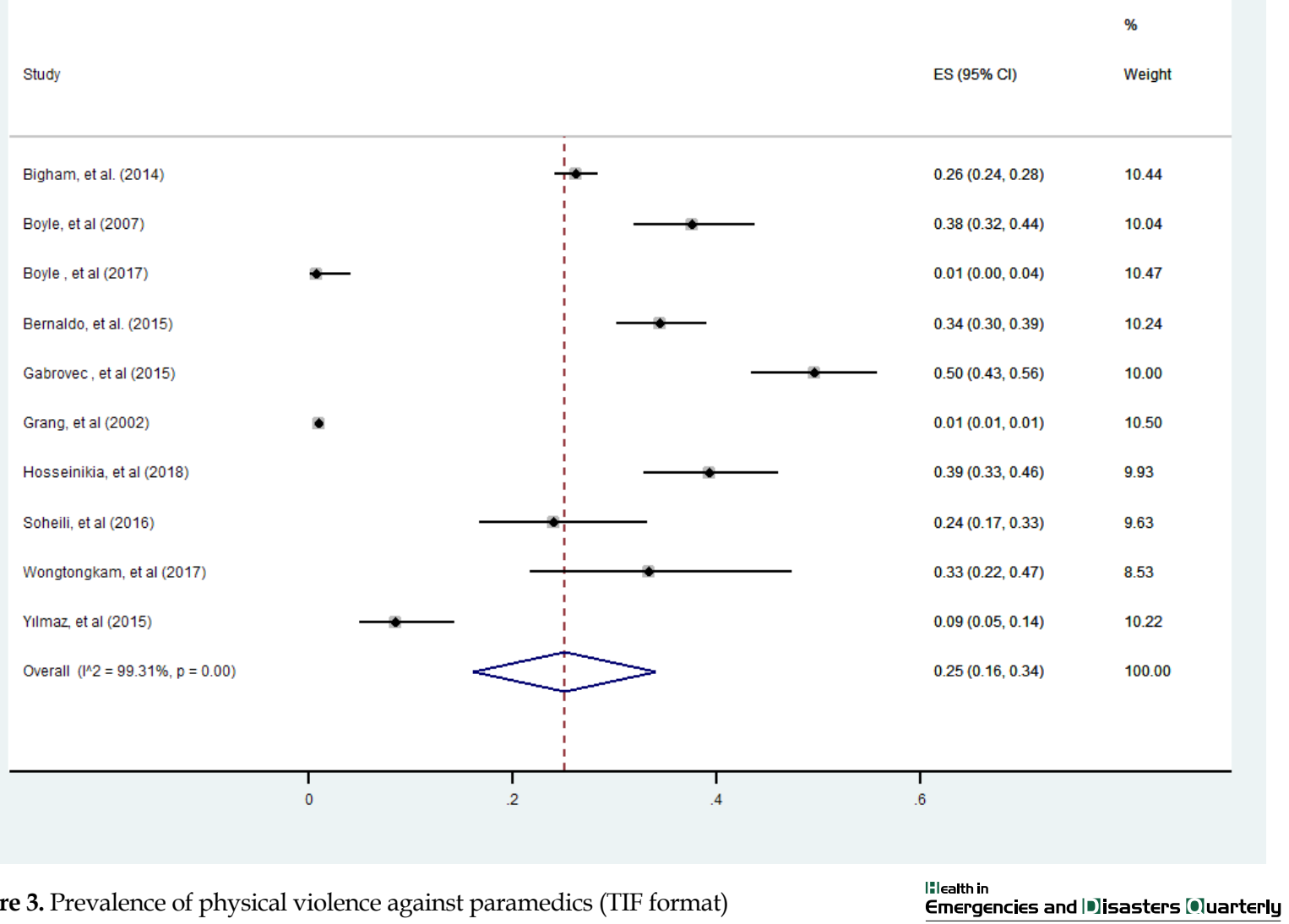

Figure 3. Prevalence of physical violence against paramedics (TIF format)

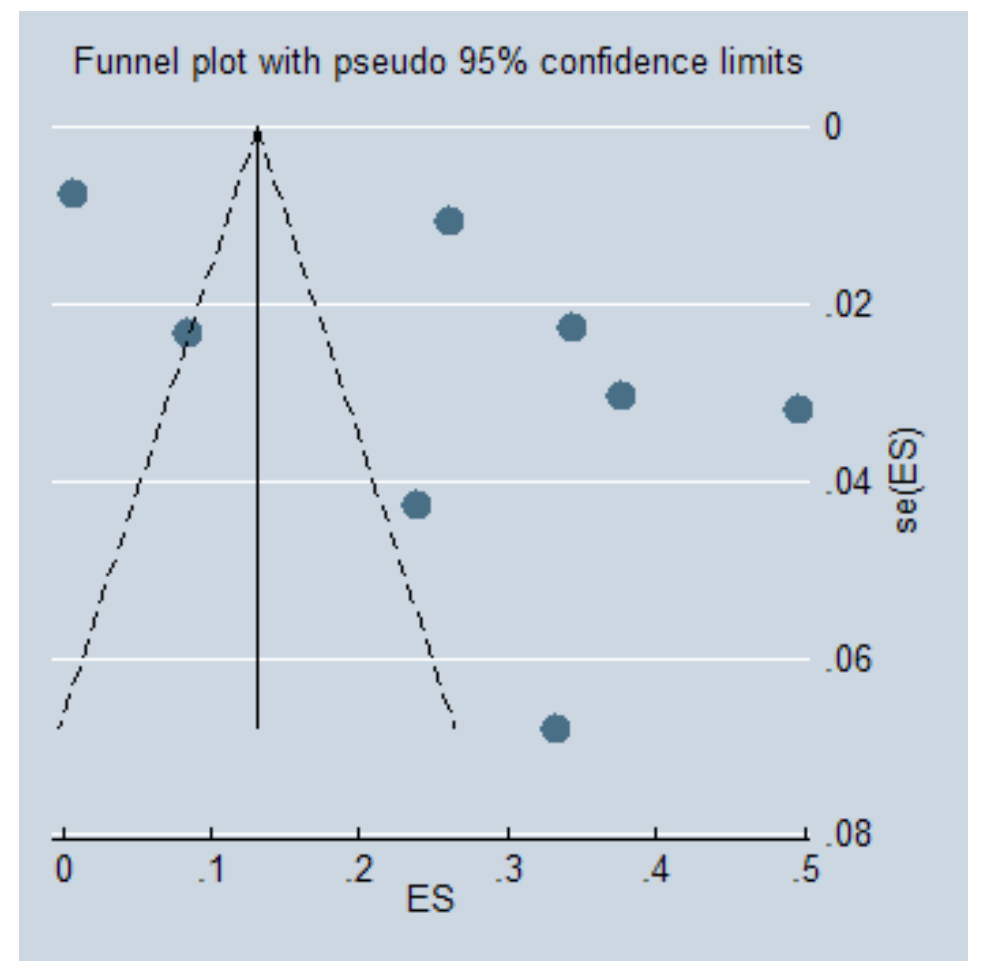

Figure 4. Test of publication bias using Funnel Plot (TIF format) 
Table 2. Prevalence of different types of violence against paramedics by gender

\begin{tabular}{|c|c|c|}
\hline \multirow{2}{*}{ Type of Violence } & \multicolumn{2}{|c|}{ Prevalence $(95 \% \mathrm{Cl})$} \\
\hline & Male & Female \\
\hline Physical & $0.26(0.19,0.32)$ & $0.26(0.11,0.41)$ \\
\hline Verbal & $0.60(0.48,0.71)$ & $0.60(0.39,0.81)$ \\
\hline Sexual harassment & $0.06(0.05,0.08)$ & $0.24(0.05,0.43)$ \\
\hline
\end{tabular}

the total heterogeneity in the meta-analysis, which was not statistically significant $(\mathrm{P}=0.368)$.

We also evaluated publication bias using the funnel plot and Egger's test. The funnel plot showed that seven studies were located out of the funnel plot (Figure 4). Moreover, the results of Egger's test $(\mathrm{P}=0.094)$ indicated a publication bias in this study.

\section{Discussion}

To the best of our knowledge, this study is the first systematic review and meta-analysis on the global prevalence of WPV against paramedics. A total of 11 papers were included in the meta-analysis. Because of the low number of eligible studies, we decided to include all studies without considering the quality score.

According to our study, a quarter of paramedics experienced physical violence worldwide, more than half of them faced verbal violence, and less than two-tenths experienced sexual harassment. These rates might increase if the timeframe of study includes the entire career life of paramedics rather than a year, as considered in most studies in this field. The estimated rates are of little value; the actual rate could be much higher [41]. The findings of Gates's study on 2042 emergency department staff of 5 hospitals showed that $65 \%$ of assaults to the staff were not reported and registered [42]. Also, the survey results on employees of a health care organization revealed that only $57 \%$ of the acts of physical violence and $40 \%$ of non-physical violence were reported to employers, of which $86 \%$ was an oral report [43]. This behavior has different reasons, one of which is the lack of clear and supportive policies and laws for reporting violence against paramedics [21]. Another reason might be that paramedics believe encountering violence is a natural and an integral part of their profession [30]. Moreover, they might be reluctant to report the violence because it may be considered a weakness, meaning they failed to handle a condition that led to the violence [30].

There were differences between the types of violence prevalent in different world regions. Europe and North

Table 3. Prevalence of different types of violence against paramedics around the world

\begin{tabular}{|c|c|c|c|c|}
\hline \multicolumn{2}{|c|}{ World Areas and Type of Violence } & \multirow{2}{*}{$\begin{array}{c}\text { Number of Studies } \\
4\end{array}$} & \multirow{2}{*}{$\begin{array}{c}\text { Number of Samples } \\
6465\end{array}$} & \multirow{2}{*}{$\begin{array}{l}\text { Mean } \pm S D \\
27.8 \pm 17.64\end{array}$} \\
\hline & Physical & & & \\
\hline \multirow[t]{3}{*}{$\begin{array}{c}\text { Europe \& North } \\
\text { America }\end{array}$} & Verbal & 4 & 6465 & $48.74 \pm 29.03$ \\
\hline & Sexual harassment & 2 & 1922 & $19.05 \pm 5.35$ \\
\hline & Physical & 3 & 436 & $23.67 \pm 16.77$ \\
\hline \multirow[t]{3}{*}{ Asia } & Verbal & 3 & 436 & $58.13 \pm 26.54$ \\
\hline & Sexual harassment & 3 & 1734 & $8.79 \pm 6.74$ \\
\hline & Physical & 3 & 447 & $23.93 \pm 12.57$ \\
\hline \multirow[t]{2}{*}{ The Middle East } & Verbal & 3 & 447 & $69.62 \pm 12.62$ \\
\hline & Sexual harassment & - & - & - \\
\hline
\end{tabular}


Table 4. Meta-regression analysis of affected factors with heterogeneity

\begin{tabular}{ccccc}
\hline Heterogeneity Source & Coefficients & Std. Err. & P & Adj R (\%) \\
\hline Publication year & -0.018 & 0.019 & 0.368 & 0.30 \\
\hline Study quality score & 0.015 & 0.018 & 0.417 & -2.85 \\
\hline Level of study & 0.036 & 0.073 & 0.637 & -11.91 \\
\hline Sampling method & 0.007 & 0.027 & 0.817 & -15.62 \\
\hline & & & $\begin{array}{c}\text { IIlealth in } \\
\text { Emergencies and [Disasters [Oluarterly }\end{array}$ \\
\hline
\end{tabular}

America had the highest levels of physical violence and sexual harassment but the lowest level of verbal violence. Asia and Australia had the lowest physical violence and sexual harassment rates and second rate for verbal violence. The Middle East had the highest rank for verbal violence and the second rank for physical violence. Totally, paramedics in Europe and North America are more at risk of WPV than other regions, while those working in Asia and Australia have the lowest risk of occupational violence. In the Middle East, paramedics experience the highest level of verbal violence and relatively a high level of physical violence. Most of these differences can be explained by different cultural and social contexts. For example, people of the Middle East are hesitant to admit sexual harassment. In this area, speaking of sex, in general, is taboo $[44,45]$. The taboo is so strong that it sometimes even prevents conducting studies on this subject. For example, the prevalence of sexual violence has not been considered in three studies of the Middle East included in our final analysis. The participants of these studies were not questioned about the exposure to sexual violence. This issue can lead to no or under-reporting tendencies across different world regions [46, 47].

There was no significant difference between men and women in terms of physical violence, nor verbal violence, or sexual harassment. However, the prevalence of sexual harassment among women was higher than men (24\% vs. 6\%). A similar pattern can be observed in most studies performed on WPV in other professions; they reported higher rates of sexual violence against women than men [48-52]. It can be discussed that in man-dominated professions and the ones that require face-to-face and direct contact with the client (i.e., patient), female employees might not receive enough protection [53-57].

The main limitation of this study was the low number of eligible articles. Because of the scarcity of eligible studies, meta-analysis was not conducted on some subtypes of violence such as bullying, intimidation, and sexual assault, and comparisons could not be made.
However, meta-analysis and comparisons were made at three main types of violence, namely physical, verbal, and sexual [7, 8, 58]. In addition, in the few included studies, in the final analysis, all critical issues such as the source of violence (predator) were not considered. However, we attempted to make quantitative descriptive analysis and comparisons of those crucial issues using more data available, such as violence by gender or by continents and areas of the world.

Although the differences in the timeframe of eligible studies in our review seem to be a limitation, it should be noted that these time frames were slightly different. Moreover, it cannot be considered a major limitation because the time span was not very wide, and it was the last year for most studies $(72 \%[n=8])$.

\section{Conclusion}

WPV in a prehospital emergency care setting is a significant problem, with evident and latent aspects and magnitude like an iceberg. Paramedics are at the highest risk of WPV among all health care professionals. This finding indicates the necessity of special attention of prehospital care administrators to reduce the risk and consequences of WPV by taking effective measures.

\section{Ethical Considerations}

\section{Compliance with ethical guidelines}

There were no ethical considerations to be considered in this research.

\section{Funding}

This research did not receive any grant from funding agencies of public, commercial, or non-profit sectors. 


\section{Authors' contributions}

Conceptualization, supervision, data analysis, and methodology: Hamidreza Shabanikiya and Mehdi Varmaghani; Writing the original draft, review, and editing: Hamidreza Shabanikiya, Mehdi Varmaghani, and Fatemeh Kokabisaghi; Data collection: All authors.

\section{Conflict of interest}

The authors declared no conflict of interest.

\section{References}

[1] Blair D. Assaultive behavior: Does provocation begin in the front office? Journal of Psychosocial Nursing and Mental Health Services. 1991; 29(5):21-6. [DOI:10.3928/0279-369519910501-06] [PMID]

[2] Jatic Z, Erkocevic H, Trifunovic N, Tatarevic E, Keco A, Sporisevic L, et al. Frequency and forms of workplace violence in primary health care. Medical Archives (Sarajevo, Bosnia and Herzegovina). 2019; 73(1):6-10. [DOI:10.5455/medarh.2019.73.6-10] [PMID] [PMCID]

[3] Seun-Fadipe CT, Akinsulore AA, Oginni OA. Workplace violence and risk for psychiatric morbidity among health workers in a tertiary health care setting in Nigeria: Prevalence and correlates. Psychiatry Rresearch. 2019; 272:730-6. [DOI:10.1016/j.psychres.2018.12.177] [PMID]

[4] Sun Z, LinSX, Wang S. An economic model of optimal penalty for health care workplace violence. Inquiry: A Journal of Medical Care Organization, Provision and Financing. 2019; 56:46958019884190. [DOI:10.1177/0046958019884190] [PMID] [PMCID]

[5] di Martino V. Relationship between work stress and workplace violence in the health sector. Workplace violence in the health sector. Geneva: WHO; 2003. https://www.who.int/ violence_injury_prevention/violence/interpersonal/WVstresspaper.pdf?ua $=1$

[6] Kennedy MA. Workplace violence: An exploratory study into nurses interpretations and responses to violence and abuse in trauma and emergency departments[PhD, dissertation]. South Africa: University of the Western Cape; 2004. http://hdl.handle.net/11394/1502

[7] Nowrouzi-Kia B, Chai M, Usuba K, Nowrouzi-Kia B, Casole J. Prevalence of type II and type III workplace violence against physicians: A systematic review and meta-analysis. International Journal of Occupational and Environmental Medicine. 2019; 10(3):99-110. [DOI:10.15171/ijoem.2019.1573] [PMID] [PMCID]

[8] Pompeii L, Schoenfisch A, Lipscomb H, Dement J, Smith C, Upadhyaya M. Physical assault, physical threat, and verbal abuse perpetrated against hospital workers by patients or visitors in six US hospitals. American Journal of Industrial Medicine. 2015; 58(11):1194-204. [DOI:10.1002/ajim.22489] [PMID]
[9] Gacki-Smith J, Juarez A, Boyett L, Homeyer C, Robinson L, MacLean SL. Violence against nurses working in US emergency departments. Journal of Nursing Administration. 2009; 39(7-8):3409. [DOI:10.1097/NNA.0b013e3181ae97db] [PMID]

[10] Bernaldo D, Piccini A, Gómez M, Cerdeira JC. Psychological consequences of aggression in prehospital emergency care: Cross sectional survey. International Journal of Nursing Studies. 2015; 52(1):260-70. [DOI:10.1016/j.ijnurstu.2014.05.011] [PMID]

[11] Bigham B, Jensen J, Tavares W, Drennan I, Saleem H, Dainty $\mathrm{K}$, et al. Paramedic self-reported exposure to violence in the Emergency Medical Services (EMS) workplace: A mixed-methods cross-sectional survey. Prehospital Emergency Care. 2014 18(4):489-94. [DOI:10.3109/10903127.2014.912703] [PMID]

[12] Maguire B, O'Meara P, O'Neill B, Brightwell R. Violence against emergency medical services personnel: A systematic review of the literature. American Journal of Industrial Medicine. 2018; 61(2):167-80. [DOI:10.1002/ajim.22797]

[13] Akbari M, Allah-Bakhshyan A, Rahmani A, Dadashzadeh A, Namdar H. [Assessing workplace violence toward EMS' personnel in prehospital settings of East Azerbaijan Province (Persian)] Iranian Journal of Forensic Medicine. 2009; 15(2):100-7. http:// sjfm.ir/article-1-188-fa.html

[14] Sands N. An ABC approach to assessing the risk of violence at triage. Australasian Emergency Nursing Journal. 2007; 10(3):1079. [DOI:10.1016/j.aenj.2007.05.002]

[15] Miller D. When you really are the first responder at the scene. Occupational Health \& Safety. 2001; 70(4):40-6. [PMID]

[16] Petzäll K, Tällberg J, Lundin T, Suserud B-O. Threats and violence in the Swedish prehospital emergency care. International Emergency Nursing. 2011; 19(1):5-11. [DOI:10.1016/j. ienj.2010.01.004] [PMID]

[17] Maguire B, Hunting K, Guidotti T, Smith G. Occupational injuries among emergency medical services personnel. Prehospital Emergency Care. 2005; 9(4):405-11. [DOI:10.1080/10903120500255065] [PMID]

[18] Maguire B, Hunting K, Smith G, Levick N. Occupational fatalities in emergency medical services: A hidden crisis. Annals of Emergency Medicine. 2002; 40(6):625-32. [DOI:10.1067/ mem.2002.128681] [PMID]

[19] Gómez-Gutiérrez M, Bernaldo-de-Quirós M, Piccini A Cerdeira J. Posttraumatic stress symptomatology in prehospital emergency care professionals assaulted by patients and/ or relatives: Importance of severity and experience of the aggression. Journal of Interpersonal Violence. 2016; 31(2):1339-54. [DOI:10.1177/0886260514555370] [PMID]

[20] Sterud T, Ekeberg O, Hem E. Health status in the ambulance services: A systematic review. BMC Health Services Research. 2006; 6:82. [DOI:10.1186/1472-6963-6-82] [PMID] [PMCID]

[21] Taylor J, Barnes B, Davis A, Wright J, Widman S, LeVasseur M. Expecting the unexpected: A mixed methods study of violence to EMS responders in an urban fire department. American Journal of Industrial Medicine. 2016; 59(2):150-63. [DOI:10.1002/ ajim.22550] [PMID] [PMCID]

[22] Brough P. Workplace violence experienced by paramedics: Relationships with social support, job satisfaction, and psychological strain. Australasian Journal of Disaster and Trauma Studies. 2005; 2005 (2):5-18. https:/ / espace.library.uq.edu.au/view/ UQ:677312 
[23] Maguire B, O’Meara P, Brightwell R, O'Neill B, FitzGerald G. Occupational injury risk among Australian paramedics: An analysis of national data. The Medical Journal of Australia. 2014; 200(8):477-80. [DOI:10.5694/mja13.10941] [PMID]

[24] Pourshaikhian M, Gorji HA, Aryankhesal A, Khorasani-Zavareh D, Barati A. A systematic literature review: Workplace violence against emergency medical services personnel. Archives of Trauma Research. 2016; 5(1):e28734. [DOI:10.5812/ atr.28734] [PMID] [PMCID]

[25] Sahebi A, Jahangiri K, Sohrabizadeh S, Golitaleb, M. Prevalence of workplace violence types against personnel of Emergency Medical Services in Iran: A systematic review and meta-analysis. Iranian journal of psychiatry. 2019; 14(4): 325-34. [DOI:10.18502/ijps.v14i4.1984]

[26] PRISMA checklist [Internet]. Available from: https:// www.elsevier.com/_data/promis_misc/ISSM_PRISMA_ Checklist.pdf

[27] Boyle M, Koritsas S, Coles J, Stanley J. A pilot study of workplace violence towards paramedics. Emergency Medicine Journal: EMJ. 2007; 24(11):760-3. [DOI:10.1136/ emj.2007.046789] [PMID] [PMCID]

[28] Boyle M, McKenna L. Paramedic student exposure to workplace violence during clinical placements- A crosssectional study. Nurse Education in Practice. 2017; 22:93-7. [DOI:10.1016/j.nepr.2017.01.001] [PMID]

[29] Gabrovec B. The prevalence of violence directed at paramedic services personnel/prevalenca nasilja nad zaposlenimi $\mathrm{v}$ resevalnih sluzbah. Obzornik Zdravstvene Nege. 2015 49(4):284-94. [DOI:10.14528/snr.2015.49.4.60]

[30] Grange JT, Corbett SW. Violence against emergency medical services personnel. Prehospital Emergency Care. 2002; 6(2):186-90. [DOI:10.1080/10903120290938526] [PMID]

[31] Hosseinikia SH, Zarei S, Kalyani MN, Tahamtan S. A cross-sectional multicenter study of workplace violence against prehospital emergency medical technicians. Emergency Medicine International. 2018; 2018:7835676. [DOI:10.1155/2018/7835676] [PMID] [PMCID]

[32] Soheili A, Feizi A, Rahmani A, Parizad N, Sheykh-Kanlou $\mathrm{J}$. The extent, nature and contributing factors of violence against Iranian emergency medical technicians. Nursing and Midwifery Studies. 2016; 5(3):e29619. [DOI:10.17795/nmsjournal29619]

[33] Wongtongkam N. An exploration of violence against paramedics, burnout and posttraumatic symptoms in two Australian ambulance services. International Journal of Emergency Services. 2017; 6(2):134-46. [DOI:10.1108/IJES-03-2017-0014]

[34] Yilmaz A, Dal O, YaylaciS, Uyanik E. Rate of exposure to violence in 112 staff in Denizli city. Eurasian Journal of Emergency Medicine. 2015; 14(3):103-6. [DOI:10.5152/ eajem.2015.90958]

[35] Yoo J, Kim J, Yoon J, Kim S. Sexual harassment and its relationship with depressive symptoms: A nationwide study of Korean EMS providers. American Journal of Industrial Medicine. 2019; 62(1):74-9. [DOI:10.1002/ajim.22924] [PMID]

[36] Farzadfar F, Delavari A, Malekzadeh R, Mesdaghinia A, Jamshidi H, Sayyari A, et al. NASBOD 2013: Design, definitions, and metrics. Archives of Iranian Medicine. 2014; 17:7-15. [MID]
[37] Sajjadi-Jazi S, Sharifi F, Varmaghani M, Meybodi H, Farzadfar F, Larijani B. Epidemiology of hyperthyroidism in Iran: A systematic review and meta-analysis. Journal of Diabetes \& Metabolic Disorders. 2018; 17(2):345-55. [DOI:10.1007/ s40200-018-0367-1] [PMID] [PMCID]

[38] Varmaghani M, Dehghani M, Heidari E, Sharifi F, Moghaddam S, Farzadfar F. Global prevalence of chronic obstructive pulmonary disease: Systematic review and meta-analysis. Eastern Mediterranean Health Journal. 2019; 25(1):47-57. [DOI:10.26719/emhj.18.014] [PMID]

[39] Varmaghani M, Farzadfar F, Sharifi F, Rashidain A, Moin M, Moradi-Lakeh M, et al. Prevalence of asthma, COPD, and chronic bronchitis in Iran: A systematic review and metaanalysis. Iranian Journal of Allergy, Asthma and Immunology. 2016; 15(2):93-104. [PMID]

[40] Varmaghani M, Rashidian A, Kebriaeezadeh A, MoradiLakeh M, Moin M, Ghasemian A, et al. National and sub-national prevalence, trend, and burden of asthma in Iran from 1990 to 2013 the study protocol. Archives of Iranian Medicine. 2014; 17(12):804-9. [PMID]

[41] Knaus C. Violence against ambos 'the tip of the iceberg' [Internet]; 2013. Available from: https://www.canberratimes.com. au/story/6149839/violence-against-ambos-the-tip-of-theiceberg/

[42] Gates D, Ross C, McQueen L. Violence against emergency department workers. The Journal of Emergency Medicine. 2006; 31(3):331-7. [DOI:10.1016/j.jemermed.2005.12.028] [PMID]

[43] Findorff M, McGovern P, Wall M, Gerberich S. Reporting violence to a health care employer. AAOHN Journal. 2005; 53(9):399-406. [DOI:10.1177/216507990505300906] [PMID]

[44] Esmaeilpour M, Salsali M, Ahmadi F. Workplace violence against Iranian nurses working in emergency departments. International Nursing Review. 2011; 58(1):130-7. [DOI:10.1111/j.1466-7657.2010.00834.x] [PMID]

[45] Gerberich SG, Church TR, McGovern PM, Hansen HE Nachreiner NM, Geisser MS, et al. An epidemiological study of the magnitude and consequences of work related violence: the Minnesota Nurses' Study. Occupational and Environmental Medicine. 2004; 61(6):495-503. [DOI:10.1136/ oem.2003.007294] [PMID] [PMCID]

[46] El-Gilany A-H, El-Wehady A, Amr M. Violence against primary health care workers in Al-hassa, Saudi Arabia. Journal of Interpersonal Violence. 2010; 25(4):716-34. [DOI:10.1177/0886260509334395] [PMID]

[47] Snyder LA, Chen PY, Vacha-Haase T. The underreporting gap in aggressive incidents from geriatric patients against certified nursing assistants. Violence and Victims. 2007; 22(3):367-79. [DOI:10.1891/088667007780842784] [PMID]

[48] AkhterS, RutherfordS, Chu C.Sufferingsinsilence:Violence against female workers in the ready-made garment industry in Bangladesh: A qualitative exploration. Womens Health. 2019; 15:1745506519891302. [DOI:10.1177/1745506519891302] [PMID] [PMCID]

[49] Ansoleaga E, Ahumada M, González-Santa Cruz A. Association of workplace bullying and workplace vulnerability in the psychological distress of chilean workers. International Journal of Environmental Research and Public Health. 2019; 16(20):4039. [DOI:10.3390/ijerph16204039] [PMID] [PMCID] 
[50] Chappell D, Di Martino V. Violence at work. $2^{\text {th }}$ ed. Geneva: International Labour Office; 2000. http://www.nzdl.org/ cgi-bin $/$ library? $=\mathrm{d}-=2$

[51] Chappell D, Di Martino V. Violence at Work. $3^{\text {th }}$ ed. Geneva: International Labour Office; 2006. https://www.ilo.org/ global/publications/ilo-bookstore/order-online/books/ WCMS_PUBL_9221108406_EN/lang--en/index.htm

[52] Rotundo M, Nguyen D-H, Sackett PR. A meta-analytic review of gender differences in perceptions of sexual harassment. Journal of Applied Psychology. 2001; 86(5):914-22. [DOI:10.1037/0021-9010.86.5.914] [PMID]

[53] Mayhew C, Chappell D. Occupational violence: Types, reporting patterns, and variations between health sectors. Australia: University of New South Wales; 2001. https://www. econbiz.de/Record/occupational-violence-types-reportingpatterns-and-variations-between-health-sectors-mayhewclaire/10001612007

[54] Murdoch M, Nichol K. Women veterans' experiences with domestic violence and with sexual harassment while in the military. Archives of Family Medicine. 1995; 4(5):411-8. [DOI:10.1001/archfami.4.5.411] [PMID]

[55] Silber A, Lane M, Morgan J, Charm S, Tharp A, Brown M. Perceptions of high-risk situations for sexual assault: Gender differences in the U.S. air force. Military Medicine. 2019; 184(S1):443-50. [DOI:10.1093/milmed/usy350] [PMID]

[56] Street AE, Gradus JL, Stafford J, Kelly K. Gender differences in experiences of sexual harassment: Data from a male-dominated environment. Journal of Consulting and Clinical Psychology. 2007; 75(3):464-74. [DOI:10.1037/0022006X.75.3.464] [PMID]

[57] Svedberg P, Alexanderson K. Associations between sickness absence and harassment, threats, violence, or discrimination: A cross-sectional study of the Swedish police. Work (Reading, Mass). 2012; 42(1):83-92. [DOI:10.3233/WOR-20121333] [PMID]

[58] Phillips J. Workplace violence against health care workers in the United States. The New England Journal of Medicine. 2016; 374(17):1661-9. [DOI:10.1056/NEJMra1501998] [PMID] 
This Page Intentionally Left Blank 